\title{
Dissolution of Associational Life? Testing the Individualization and Informalization Hypotheses on Leisure Activities in The Netherlands Between 1975 and 2005
}

\author{
Erik van Ingen $\cdot$ Paul Dekker
}

Accepted: 18 March 2010/Published online: 8 April 2010

(C) The Author(s) 2010. This article is published with open access at Springerlink.com

\begin{abstract}
In this paper we examine whether individualization and informalization processes have occurred in the field of leisure in The Netherlands, by analyzing the social context of a wide range of activities between 1975 and 2005. We find that the choice of a particular leisure context is dependent on education, gender, year of birth, age and time pressure. We find evidence for informalization, but - contrary to popular belief-not for individualization. The informalization trend follows a pattern of cohort replacement, and is also caused by a rise in the average education level in the population. Our findings imply that research on civil society, community and social capital should not only be concerned with membership rates, but also with participation in alternative social contexts.
\end{abstract}

Keywords Voluntary association - Informal group - Social context · Time use study

\section{Introduction}

In sociology and political science, there have long been concerns about the extent of people's involvement in communities, their contributions to voluntary organizations, their interest and activity in politics, and other kinds of pro-social behaviour. These worries can be summarized as the "decline-of-community thesis" (Paxton 1999, p. 88). However, despite the fact that these concerns are very persistent, the empirical evidence seems to be ambiguous at best (Fischer 2005; Rotolo 1999). A popular indicator in studying these changes is membership of voluntary associations. However, while convenient, this is a limited measure (Stolle and Rochon 1998); some authors have therefore suggested adopting a broader perspective, in which other, informal alternatives are also taken into account (Schudson 2006; Stolle et al. 2005). In this paper, we contribute to this wider

E. van Ingen $(\varangle) \cdot$ P. Dekker

Tilburg University, Tilburg, The Netherlands

e-mail: e.j.vaningen@uvt.nl

P. Dekker

The Netherlands Institute for Social Research I SCP, The Hague, The Netherlands 
perspective by studying associational membership alongside other contexts in the field of leisure. Based on information about people's leisure activities in The Netherlands between 1975 and 2005, we seek to ascertain whether informal and individual activities have become more important (at the expense of associational activities). We refer to these processes as informalization and individualization.

Voluntary associations are often seen as a crucial part of a healthy community and an important aspect of citizens' involvement in democracy (e.g. Putnam 2000). Although voluntary associations may have special functions, the emphasis on associational involvement as the key indicator of social capital also results from practical considerations: it is relatively easy to measure and is available in a large number of surveys. Informal groups, on the other hand, "are so all-pervasive, loose-knit, changeable, amorphous, and numerous that it is difficult to study them" (Newton 1999, p. 11). Taken together, “... associational memberships have become the indicator of choice for examining the rate of formation or destruction of social capital" (Stolle and Rochon 1998, p. 48).

We argue that examining voluntary association participation alone is insufficient and can lead to biased conclusions about decline-of-community. As an example, suppose we witness a decline in sports club participation over the years; could we then conclude that a process of individualization is taking place? It depends on the kind of substitutions that are occurring. People may have swapped club life for practicing sports alone in their own homes; that means an exchange of associational for individual activities, which is our interpretation of individualization. However, other things may have happened; people may for example have swapped sports activities for non-sports activities. Would that still be individualization? We argue that it would not, since people are not turning away from voluntary associations, but are turning away from sports. Moreover, people may have exchanged the context of a club or association for an informal group, drawn from their social networks. This is informalization rather than individualization, and does not necessarily mean decline-of-community. A thorough test of the decline-of-community thesis needs to include (trends in) alternative contexts in addition to associational involvement. In summary, individualization refers to a growing share of leisure activities performed individually, and similarly, informalization refers to a growing share of leisure activities performed in informal groups. In theory, we could also find a rise in the share of leisure activities performed in voluntary associations. For lack of a suitable term, we will refer to this as "an increased importance of voluntary associations".

As well as the trends in the social context of leisure activities, we will also analyze who chooses certain social contexts. It has been argued that modernization processes drive changes in civic participation (Dekker 2004; Fuchs and Klingemann 1995). As individual autonomy grows and work and family life become more demanding, citizens start to look for more flexible and on-demand alternatives to associational involvement. In line with these ideas, we analyze different cultural and structural factors and the way in which they affect people's preference for a certain social context in their leisure time. Finally, we try to explain the trends by looking at changes in population characteristics.

\section{Decreasing Memberships, Individualization, Informalization}

The decline-of-community thesis has seen a strong rise in popularity as a result of the publications by Putnam (1995a, b, 2000), who concluded that civic engagement has declined in the United States since-roughly - the Second World War. Important indicators of this trend are participation in political, religious and leisure associations. Although 
many scholars have been inspired by the work of Putnam, his claims are still the subject of animated scientific debate.

Paxton (1999) concludes that participation in both formal and informal types of association have been stable in the US in recent decades. Fischer (2005) comes to similar conclusions. On the other hand, Skocpol (2003) concludes from a historical analysis that several aspects of "classic civic America" have disappeared (although at the same time she warns us that many of the nostalgic images of civic engagement of the past are misconceived), while Andersen et al. (2006) showed that since 1975 Americans have spent a shrinking proportion of their time budget on civic associations.

Critics have suggested a shift from formal membership of voluntary associations to more unorganized individual and informal activities with similar content or similar civic impact (Schudson 1998, 2006). Shifts in political participation are an example:

Participation in informal local groups, political consumerism, involvement in transnational advocacy networks, the regular signing and forwarding of email petitions, and the spontaneous organizations of protests and rallies are just a few examples of the growing importance of informal organization, individualized action, and network mobilization. (Stolle et al. 2005, p. 250)

This shift has also been witnessed in another aspect of associational involvement, namely volunteering. Hustinx and Lammertyn (2003) suggest the rise of new styles of volunteering: a "reflexive style"-driven by individual preferences and shaped through occasional involvement in a diversity of settings - is emerging next to the old "collective style" model of volunteering. On the whole, "present-day volunteer efforts appear to occur on a more sporadic, temporary, and non-committal basis" (p. 168).

In general, less empirical work has been carried out on informalization than on individualization. The fact that informal association is harder to define and measure may partly explain this. Informal groups are "loose and amorphous networks of individuals who come together on a casual basis and at irregular times to play darts, talk about football, discuss a novel, raise consciousness, offer mutual support, or play a scratch game of football in the park" (Newton 1999, p. 11). They lack fixed rules of membership or governance (Kwak et al. 2004), causing "[...] only the weakest of obligations" (Wuthnow 1994). They are "defined by the ties between individuals", whereas formal associations "survive beyond any particular member" (Paxton 1999, p. 100).

The rise of the small-group movement in the United States (Wuthnow 1994) is an example of informalization. According to the author, it is a "quiet revolution", and a response to dissatisfaction with the "general breakdown of traditional support structures" (p. 5). Self-help groups are one of the most important examples of these small groups. The rise of small groups is part of a broader development, in which people increasingly prefer 'loose connections' over more long-lasting and demanding forms of social participation (Wuthnow 1998).

Individualization and informalization processes have also been witnessed in the field of leisure. Putnam (2000) suggested that informal groups are taking over the role of clubs with regard to bowling. In fact, this is the way in which the title of his well-known book should be explained:

Strictly speaking, only poetic license authorizes my description of non-league bowling as 'bowling alone.' Any observant visitor to her local bowling alley can confirm that informal groups outnumber solo bowlers... On the other hand, league bowling, by requiring regular participation with a diverse set of acquaintances, did 
represent a form of sustained social capital that is not matched by an occasional pickup of the game. (Putnam 2000, p. 113)

O'Conner (2007) reaches similar conclusions in the case of cycling; he observes an increase in "[...] informal, unorganized bunch rides" (O'Conner 2007, p. 86). Halpern (2005) concluded more generally that involvement in sports and exercise have gone up, but that participation in team sports has gone down, and that similar processes are occurring in the field of music.

Given the above ideas as expressed in the literature, we expect to find indications of: (a) individualization and (b) informalization in the field of leisure. Or, in other words, we expect that - between 1975 and 2005-the share of individual and informal group activities will have increased compared to the share of activities in voluntary associations.

\section{Explaining the Choice of a Given Context}

The next step is to understand the choice of the associational, informal group and individual context. We propose an explanation along two lines, and argue that both cultural and structural factors are important. Since some of these factors changed during the period under study, this may have resulted in changed needs and opportunities, which in turn may explain the trends.

The cultural aspects of the explanation stem from ideas about modernization by Beck (e.g., Beck and Beck-Gernsheim 2002) and Inglehart (e.g., 1997), among others. Their use of the term 'individualization' is more encompassing than ours, indicating a growing importance of individual autonomy and responsibility, more emphasis on expressive values, detraditionalization, and decreasing loyalty to institutions (Bauman 2002; Inglehart and Baker 2000). As a result of these processes, people may no longer automatically accept the fixed structures of voluntary associations, with activities on set days and at set times, but may instead want to engage in activity at a time of their own choosing. Hustinx (2005) concludes that, the more "individual, short-lived, noncommittal, and highly results-oriented volunteer involvement" is the result of "broader modernization and individualization processes" (p. 624).

These cultural shifts supposedly manifest themselves as "intergenerational value change" (Inglehart and Baker 2000, p. 42). According to this argument, the more individualistic values - with the emphasis on freedom of choice and self-development-are first adopted by the younger generations. In their formative periods (roughly until the age of 25), generations are more likely to adjust to changes in and influences from their environment. Thereafter, it is argued that their values are largely fixed. For the current paper this implies that if associational changes are driven by shifts towards more modern values, younger cohorts should display different preferences for social settings from older cohorts, and be less inclined to participate in the formal settings of voluntary associations.

Another aspect of cultural change is the declining influence of the Church on people's everyday lives, as indicated for example by lower levels of conventional religious participation (Inglehart and Baker 2000). This is particularly important in The Netherlands, where secularization forces have been strong (De Hart 2001), and where the decline in religious participation is one of the most important aspects of detraditionalization (De Beer 2007). It is likely that the importance of associational membership has also diminished along with this process, as associations were connected to the religious denominations for most of the $20^{\text {th }}$ century. A process known as 'pillarization' divided many aspects of 
society vertically; many societal institutions (including voluntary associations) existed in separate Catholic, Protestant, social democratic and liberal guises. The reasoning here is that people who are strongly integrated in religious communities will feel more obliged to participate in voluntary associations than those who are not.

In summary, we expect that the choice of social contexts for leisure activities has been subject to cultural change, as indicated by differences resulting from cohort membership (younger cohorts will more often choose informal and individual activities), church membership (those who often attend church exhibit more associational activities) and adherence to values of self-development (positively related to the informal and individual context).

Apart from these cultural factors, several structural factors influence the choice of a given social context. There are gender differences in the composition of social networks. According to Lin (2001), women's networks are smaller, contain higher proportions of relatives and neighbours, and smaller proportions of friends and co-workers. The traditional role of women in the household and community also results in different modes of social participation: they are generally more involved in informal activities than in voluntary associations and organizations (Paxton et al. 2007; Stolle et al. 2005; Wollebaek and Selle 2005).

These things have clearly changed. Women's increased labour market participation has reduced their average level of activity in the household and community. As a result, women's leisure participation ought to resemble men's leisure participation more than before. Women face increasing time pressure and fragmentation, as a result of combining work and family life, with higher expectations and standards in both domains (e.g., Van der Lippe 2007). An increased demand for flexible social contexts (i.e. individual or informal activities) may be the result of those changes. We expect working women to carry out a larger share of their leisure activities individually than non-working women.

Other factors also contribute to time pressure and fragmentation, which in turn demand flexible social settings. Some scholars assert that people's working, family and social lives no longer take place within one place or community, but are increasingly scattered across different localities (Castells 2000; Wellman 2001). They argue that this trend, which is indicated for example by increased mobility, is likely to lead in turn to changes in social participation (Glanville 2004; Putnam 2000; Ryan et al. 2005). The process whereby time pressure causes problems in the coordination of (social) activities is also referred to as $d e-$ routinization (Southerton and Tomlinson 2005).

Finally, education is known to affect social participation. The highly educated have larger social networks and better social skills than the lower-educated (Lin 2001); this enhances their associational involvement (Gesthuizen et al. 2008), but also their opportunities for organizing their own activities and company. The more pro-social orientation by the highly educated implies that they undertake fewer individual (leisure) activities.

In summary, we expect that the choice of leisure contexts is partly the result of structural differences, such as those between men and women (the latter are more inclined to choose individual and informal activities), those resulting from the combination of work and household tasks (more informal or individual activities), those resulting from time pressure and fragmentation (also more informal and individual activities), and those resulting from educational attainment (the better-educated undertake fewer individual activities).

The factors mentioned in this section may drive the trends of individualization and/or informalization, as their distributions in the population are subject to change. For instance, educational expansion or secularization change the average education level and degree of 
religiosity in the population. Given that the highly educated and the religious have distinct patterns of participation, this may drive trends on the aggregate level. We will explore these possibilities in our final analysis.

\section{The Case of The Netherlands}

Participation levels in The Netherlands are among the highest in the world, as regards both involvement in voluntary associations (Curtis et al. 2001), and in informal networks (Pichler and Wallace 2007). The available data on trends in participation in voluntary association show that the evidence for a general decline is weak; over the last 25 years, membership rates and active involvement have remained stable, except for a few very specific associations (De Hart 2005; De Hart and Dekker 1999). On the other hand, there are indications that younger cohorts spend less time in voluntary associations (Van Ingen 2008).

The Netherlands is an interesting case to study, as it is among the countries that are "close to the cutting edge of cultural change" (Inglehart and Baker 2000, p. 31). As a result of this high level of modernization, one would expect individualization and informalization trends in associational life to be very visible in The Netherlands. In the field of politics, this was confirmed by Dekker and Hooghe (2003), who concluded that a shift has been taking place from formal political participation to less hierarchically organized forms of participation in political and societal life.

\section{Data and Techniques}

The Dutch Time Use Survey (DTUS) is used for the analyses in this paper (Breedveld 2000). This dataset is unique both in the large time span covered and the level of detail with which leisure activities and their social settings are recorded. It was conducted seven times between 1975 and 2005, and for each edition a new sample was drawn which was representative of the Dutch population aged 12 years and older. For the present study, the seven waves were pooled into one dataset, giving a sample size of 17,704 respondents. The survey consists of a questionnaire and a diary section; most information used in the current paper stems from the former. Owing to the high level of respondent input required, response rates tend to be somewhat lower than in other surveys in The Netherlands. Nonetheless, there is no evidence that the response is different from other surveys, or that bias occurs according to how busy people are (Van Ingen et al. 2009).

\subsection{Dependent Variables}

In the DTUS, respondents were asked whether they performed certain leisure activities. Although it is impossible to be exhaustive, we believe that most of people's leisure activities were captured by this list of approximately 50 different pastimes. They were subdivided into three fields: sports, artistic and cultural activities, and hobbies. There was no reference to the period in which the activity took place. For all the activities, respondents were asked whether they performed the activity and they were asked to record the kind of context in their answer (see next paragraph). E.g., for volleyball, the question was: 'Do you play volleyball?'. Throughout the years, the list of items included has remained largely uniform, although items which attracted little response were sometimes compiled 
into broader categories. There were various items capturing residual categories of 'other activities' in all editions of the survey. Sports activities were captured by the following items: soccer, hockey, field or indoor handball, other field sports, volleyball, badminton, squash, fitness/aerobics/gymnastics, indoor soccer, other indoor sports, running/jogging, rollerblading/skating, swimming, tennis, cycling/walking, golf, and other sports. For artistic and cultural activities the items were: (playing) piano, electronic organ, drums, guitar, other plucked instrument, recorder, other wind instrument, percussion instrument, string instrument, other musical instrument, photography/filming, painting/drawing, moulding/pottery, and theatre/musical/ballet. Hobbies included the following items: jobs in and around the home, model-making, tinkering with radios etc., handicrafts, keeping an aquarium, cultivating or caring for plants, breeding or keeping dogs/cats/other animals, gardening in own garden, gardening on allotment, sewing/needlework, collecting stamps, collecting something else, doing crosswords, doing jigsaws, following courses for enjoyment (e.g. fine cuisine), working or playing on a computer, reading as a hobby, other hobbies, and watching videos (as a hobby).

Respondents were asked to record the kind of setting in which the activities took place. For each item, the response possibilities were: (1) no (did not perform activity); (2) yes, in a club/voluntary association; (3) yes, in another kind of group; (4) yes, performed it alone. Respondents were allowed to pick multiple options, but this was rarely done. In the analyses, we mostly used the (overall) counts of options $2-4$.

These data gave us a very detailed overview of trends in leisure activities and their contexts. However, questions may still arise as to the precise meaning of the term 'other kind of group' (option 3). Our initial interpretation was that this category should capture the informal groups of friends, family and acquaintances that make up the regular company during leisure activities in everyday life, but in the DTUS dataset we did not have the possibility of checking this assumption. We therefore consulted another source that is representative for the Dutch population: the 2003 Amenities and Services Utilisation Survey (AVO) (Social and Cultural Planning Office 2003). This survey contained a question about sports, with a similar distinction between voluntary associations and other kinds of contexts, but with more detailed information about their composition. $83 \%$ of these groups consisted of friends, family or a combination of both, sometimes combined with individual activities (9\%). Other options were: work/company setting (3\%) or student facilities $(1 \%)$. The remainder $(4 \%)$ consisted of a number of rare combinations of multiple contexts.

\subsection{Independent Variables}

The variable year indicated the year of measurement, ranging from 0 (1975) to 6 (2005). In other words, each unit reflects a five-year change. Women and employed are straightforward dummy variables. Education was measured on a 7-point ordinal scale, ranging from primary education to university degree, and representing the main educational categories in The Netherlands. Cohorts are operationalized in five categories representing year of birth: up to 1930, 1931-1945, 1946-1960, 1961-1975 and 1976 or later. Age is a continuous variable, ranging from 12 to 100 years. It is used as a control variable, as a means of eliminating the variation in the cohort effects that is caused by aging. Age-squared was added to capture a possible non-linear relationship. Church attendance was measured on an 8-point scale, asking about the number of church visits per year. Combining tasks indicates whether someone combines a job (12 h or more per week) with household tasks (12 h or more per week). Time problems consists of a scale (Cronbach's Alpha $=.75$ ) made up of 
three items: (1) "In my free time I often don't have the time to do the things I actually want"; (2) "It takes a lot of effort to plan my leisure activities"; and (3) "Too many of my leisure activities are dispersed". The values items were measured on a 5-point scale ranging from very unimportant to very important.

The descriptive statistics of the dependent variables, as shown in Table 1, can be interpreted as follows: on average, people registered 0.49 leisure activities in voluntary associations, 0.44 leisure activities in informal groups and 5.03 individual leisure activities. The proportion of leisure activities performed in the context of a voluntary association was 0.09 on average. Similarly, the proportion of activities undertaken in informal groups was 0.07 and the proportion of individual activities was 0.85 . The time problems and values variables were available in a limited number of editions of the survey, and thus show a much smaller sample size $(\mathrm{N})$.

\subsection{Analytical Strategy}

First, we analyzed the trends in the social context of leisure activities using a linear regression model (OLS estimated), with the absolute number of activities as dependent variable (Table 2).

Second, we examined the proportions of associational, informal and individual activities - that is, the share of a certain context in relation to the sum of all leisure activities (e.g. for informal activities: $\left.\Sigma_{\text {informal }} /\left(\Sigma_{\text {associational }}+\Sigma_{\text {informal }}+\Sigma_{\text {individual }}\right)\right)$. By using proportions, selection problems are circumvented; some people may register more activities in all contexts, whereas we are interested in the importance of a particular context given the leisure activities that are performed. Trends and correlates with regard to these proportions were then explored (Table 3).

Table 1 Descriptive statistics of most important variables

\begin{tabular}{|c|c|c|c|c|c|}
\hline Variable & $\mathrm{N}$ & Mean & SD & Min & $\operatorname{Max}$ \\
\hline Leisure: voluntary associations & 17,704 & 0.49 & 0.78 & 0 & 13 \\
\hline Leisure: informal groups & 17,704 & 0.44 & 1.01 & 0 & 16 \\
\hline Leisure: individual activities & 17,704 & 5.03 & 2.60 & 0 & 19 \\
\hline Proportion associational & 17,546 & 0.09 & 0.15 & 0 & 1 \\
\hline Proportion informal & 17,546 & 0.07 & 0.14 & 0 & 1 \\
\hline Proportion individual & 17,546 & 0.85 & 0.20 & 0 & 1 \\
\hline Year (of measurement; $1975=0$ ) & 17,704 & 3.05 & 1.78 & 0 & 6 \\
\hline Women & 17,704 & 0.57 & 0.50 & 0 & 1 \\
\hline Employed & 17,676 & 0.47 & 0.50 & 0 & 1 \\
\hline Education & 17,583 & 3.26 & 1.44 & 1 & 6 \\
\hline Cohorts & 17,704 & 2.91 & 1.16 & 1 & 5 \\
\hline Age & 17,704 & 39.24 & 17.00 & 12 & 100 \\
\hline Church attendance & 17,704 & 2.26 & 2.89 & 0 & 8 \\
\hline Combining tasks & 17,704 & 0.28 & 0.45 & 0 & 1 \\
\hline Time problems & 7,137 & 2.68 & 0.99 & 1 & 5 \\
\hline Values: relaxing \& hobbies important & 1,394 & 4.76 & 0.62 & 1 & 5 \\
\hline Values: social contacts important & 1,455 & 4.55 & 0.64 & 1 & 5 \\
\hline Values: self-development important & 1,461 & 4.07 & 0.85 & 1 & 5 \\
\hline
\end{tabular}


Table 2 Regression of leisure participation (frequency) on year of measurement (entries are unstandardized coefficients)

\begin{tabular}{lllcc}
\hline & Leisure & Sports & Arts \& culture & Hobbies \\
\hline $\begin{array}{l}\text { Voluntary associations } \\
\text { Year }\end{array}$ & 0.003 & $0.006^{*}$ & 0.000 & \\
$\quad$ Intercept & 0.484 & 0.345 & 0.051 & $-0.004^{* *}$ \\
Informal groups & & & & 0.088 \\
$\quad$ Year & $0.032^{* *}$ & $0.030^{* *}$ & 0.002 & 0.000 \\
$\quad$ Intercept & 0.340 & 0.100 & 0.063 & 0.177 \\
Individual activities & & & & $-0.042^{* *}$ \\
$\quad$ Year & $0.026^{* *}$ & $0.079^{* *}$ & $-0.011^{* *}$ & 3.984 \\
Intercept & 4.950 & 0.160 & 0.806 & \\
\hline
\end{tabular}

$\sim p<.10 ; * p<.05 ; * * p<.01$

Finally, we analyzed whether changes in the population as regards the determinants of the social context (e.g. the increase in highly educated individuals) explain the trends (Table 4). We regressed the proportion of informal activities on the year of measurement, and examined in subsequent models whether the size of this coefficient is reduced (intermediation) after entering explanatory variables.

\section{Results}

The interpretation of the results in Table 2 is straightforward. Each row and column represents a separate regression, i.e. the results of twelve regression analyses are shown. The variable year indicates year of measurement, ranging from 0 (1975) to 6 (2005). As a result, the intercepts have a useful interpretation; they represent the average number of activities (in a given context) in the year 1975 (when year $=0$ ). Thus, the first intercept can be interpreted as follows: in 1975, people performed 0.484 leisure activities in voluntary associations on average. The results in the first column are the activities added together across all three domains. The trend in associational leisure activities is very small: every 5 years 0.003 additional activities in voluntary associations were undertaken in the sample (or a 3\% increase between 1975 and 2005), which is not significantly different from zero. The picture is different for informal group activities. People performed 0.340 leisure activities in informal groups in 1975, and in every year of measurement (when predicted linearly) this increased by 0.032 . This means that in 2005 (year $=6$ ), the average number had risen to approximately $0.534(0.340+6 \times 0.032$ (difference occurs as a result of rounding off the numbers)), which equates to a $57 \%$ increase. The third row shows that, in general, most leisure activities are performed individually. In 1975, people performed 4.950 individual leisure activities, and there was a significant increase $(b=0.026$; $p=.020)$ over the years: between 1975 and 2005 the number of activities increased by $0.153(6 \times 0.026)$. This increase is very small, however, corresponding to a $3 \%$ change (in 30 years).

Next, we subdivided our dependent variables. Trends turned out to be different according to the type of leisure activities under study. Most notable are the developments in sports. As can be seen in Table 2, the number of sports activities increased in all three contexts. However, the magnitude of the changes is somewhat varied. This can be shown 
Table 3 Regression analyses of proportions associational, informal and individual activities on determinants

\begin{tabular}{|c|c|c|c|c|c|c|}
\hline & \multicolumn{2}{|c|}{ Proportion associational $^{\mathrm{a}}$} & \multicolumn{2}{|c|}{ Proportion informal $^{\mathrm{b}}$} & \multicolumn{2}{|c|}{ Proportion individual $^{\mathrm{C}}$} \\
\hline & Model I & Model II & Model III & Model IV & Model V & Model VI \\
\hline Year & .000 & - & $.004 * *$ & - & $-.005^{* *}$ & - \\
\hline \multicolumn{7}{|l|}{ Cohorts } \\
\hline Until 1930 (reference) & & 0 & & 0 & & 0 \\
\hline 1931-1945 & & $.011^{*}$ & & $.015^{* *}$ & & $-.026^{* *}$ \\
\hline 1946-1960 & & -.003 & & $.020 * *$ & & $-.016^{*}$ \\
\hline 1961-1975 & & $-.012 \sim$ & & $.027 * *$ & & $-.015 \sim$ \\
\hline From 1976 & & .009 & & $.046^{* *}$ & & $-.055^{*}$ \\
\hline Age & & $-.006 * *$ & & $-.002 * *$ & & $.008 * *$ \\
\hline $\operatorname{Age}^{2}(/ 100)$ & & $.005^{* *}$ & & $.002 * *$ & & $-.007 * *$ \\
\hline Church attendance & & -.000 & & $.001 *$ & & -.001 \\
\hline Women $($ ref $=$ men $)$ & & $-.021 * *$ & & -.003 & & $.023 * *$ \\
\hline Employed (ref $=$ other) & & .003 & & -.002 & & -.001 \\
\hline Combining tasks & & $-.007 *$ & & -.003 & & $.010^{*}$ \\
\hline Education & & $.006^{* *}$ & & $.006^{* *}$ & & $-.012 * *$ \\
\hline Time problems ${ }^{\mathrm{d}}$ & & $-.007 * *$ & & .003 & & $.004 \sim$ \\
\hline \multicolumn{7}{|l|}{ Values $^{\mathrm{d}}$} \\
\hline Relaxing \& hobbies important & & -.005 & & -.003 & & .008 \\
\hline Social contacts important & & .006 & & -.006 & & .000 \\
\hline Self-development important & & $-.009^{*}$ & & .003 & & .006 \\
\hline
\end{tabular}

${ }^{a}$ Model I: $\mathrm{N}=17,546, \mathrm{R}^{2}=.000 ;$ Model IIa: $\mathrm{N}=17,399, \mathrm{R}^{2}=.056$; Model IIb: $\mathrm{N}=1,376, \mathrm{R}^{2}=.027$; Model IIc: $\mathrm{N}=7,050, \mathrm{R}^{2}=.063$

b Model III: $\mathrm{N}=17,546, \mathrm{R}^{2}=.003$; Model IVa: $\mathrm{N}=17,399, \mathrm{R}^{2}=.025$; Model IVb: $\mathrm{N}=1,376$, $\mathrm{R}^{2}=.016 ;$ Model IVc: $\mathrm{N}=7,050, \mathrm{R}^{2}=.021$

c Model V: $\mathrm{N}=17,546, \mathrm{R}^{2}=.002 ;$ Model Va: $\mathrm{N}=17,327, \mathrm{R}^{2}=.063$; Model $\mathrm{Vb}: \mathrm{N}=1,369$, $\mathrm{R}^{2}=.035 ;$ Model Vc: $\mathrm{N}=7,050, \mathrm{R}^{2}=.077$

${ }^{\mathrm{d}}$ Results from separate analysis, data were only available in a few waves (effects controlled for gender, employment, combining tasks, education, age, age ${ }^{2}$, church attendance)

$\sim p<.10 ; * p<.05 ; * * p<.01$

by computing the relative change over the years; between 1975 and 2005, the average number of sports activities in voluntary associations increased from 0.345 to 0.383 . The other two trends are more pronounced: there was an increase in sports activities in informal groups, which went up from 0.100 to 0.280 , and there was a large increase in individual sports activities, from 0.160 in 1975 to 0.634 in 2005 . All three trends are significantly different from zero.

The trends in artistic and cultural leisure activities are different. As Table 2 shows, there was no significant trend for associational and informal group activities, whereas the number of individual activities decreased $(b=-0.011)$. However, this trend is not strong; between 1975 and 2005, it equals $-0.067(6 \times-0.011)$, or an 8\% decrease. Finally, the last column in Table 2 shows the results for hobbies. These leisure activities are typically performed individually; the intercept of individual activities $(b=3.984)$ is far greater than the intercepts of associational and informal group activities $(b=0.088,0.177)$. There was a decrease in activities in voluntary associations of $0.025(6 \times-0.004)$, or $28 \%$. 
Table 4 Regression of proportion informal activities on year of measurement and explanatory variables

\begin{tabular}{|c|c|c|c|c|}
\hline & Model I & Model II & Model III & Model IV \\
\hline Year of measurement & $.004 * *$ & -.000 & $.005^{* *}$ & $.002 * *$ \\
\hline \multicolumn{5}{|l|}{ Cohorts } \\
\hline \multicolumn{5}{|l|}{ Until 1930 (reference) } \\
\hline $1931-1945$ & & $\mathrm{~V}$ & & \\
\hline 1946-1960 & & $\mathrm{V}$ & & \\
\hline $1961-1975$ & & $\mathrm{~V}$ & & \\
\hline From 1976 & & $\mathrm{~V}$ & & \\
\hline Age & & & $\mathrm{V}$ & \\
\hline $\operatorname{Age}^{2}(/ 100)$ & & & $\mathrm{V}$ & \\
\hline Education & & & & $\mathrm{V}$ \\
\hline Change coefficient $(\%)$ & - & $-102 \%$ & $+25 \%$ & $-44 \%$ \\
\hline
\end{tabular}

Simultaneously, a very small decrease in the number of individual activities occurred (approximately 6\% $(6 \times-0.042 / 3.984))$.

These numbers are interesting in themselves, but-as we have argued in the introduction of this paper-our conceptualizations of individualization and informalization concern shares of activities, or relative numbers. Although the information about the share of individual or informal group activities can be calculated from Table 2, it is more convenient to calculate proportions (as explained in the 'data' section). Table 3 presents the analyses of these proportions.

First, we analyzed the trends in the proportions of associational, informal group and individual activities for the entire field of leisure (models I, III, and V). Contrary to our expectations, we found a decrease in the share of individual activities $(b=-.005)$, which went hand in hand with an increase in the share of informal activities. The proportion of associational activities did not change. In other words, our first conclusion is that between 1975 and 2005 there are signs of informalization, but not of individualization. Note that one proportion is always the inverse of the other two; two regression models can provide all the information. However, we show all three for the sake of easier interpretation.

Next, we explored factors that may explain the choice of a given context for leisure activities. No clear cohort patterns emerged for the proportions of associational and individual activities (which contradicts our expectations), but cohorts clearly differed in their choice of informal group activities: the share of leisure activities in informal groups is larger for every younger cohort. Age and age-squared were included as control variables (to eliminate ageing from the cohort effect). There was not much life-course variation in the proportion of informal activities, but an age effect occurred with regard to the proportions of associational and individual activities: the former decreased until age 55-60 and then remained more or less stable, whereas the latter followed the opposite pattern. This may be due to the fact that people in their 30 and $40 \mathrm{~s}$ are in the busiest phase of their lives, which constrains their choices, making individual activities a more convenient choice than associational activities.

The frequency of church visits had a positive effect on the proportion of informal activities and no effect on individual activities or associational activities. Although voluntary associations had a strong connection to the religious denominations in The Netherlands in recent decades, church attendance does not lower the shares of informal and individual activities. The positive effect on the proportion of informal activities was small, given the standard deviation of church attendance $(\mathrm{SD}=2.89$; see Table 1$)$. 
In the next rows of Table 3 are three structural factors which we expected to affect the choice of certain contexts: gender (women), employment, and combination of tasks. Whether or not people were employed did not lead to different choices in the context of leisure activities. Gender and task combination showed the expected pattern: a negative effect on associational activities and a positive effect on individual activities. Informal group activities are unaffected by these indicators. Similarly, people with lots of time problems have a smaller share of associational activities and a higher share of individual activities. A clear pattern emerges from these results: structural characteristics constrain the choice for the associational context, and people who have demanding diaries are more likely to choose individual leisure activities. Informal group activities remain unaffected by these factors, however.

Education also explains part of the choice in favour of a particular context. Where respondents' education level was higher, their proportion of social activities (associational + informal) was also higher, at the expense of individual activities.

Finally, we tested the effects of three values to which respondents could subscribe. The results are shown in the bottom block of Table 3 (which is a separate analysis; these indicators were not available in all measurement years). In general, these values do not have strong effects. The importance of relaxation and hobbies and the importance of social contacts did not affect our dependent variables. However, there was a negative relationship between the importance of self-development and the choice of associational context. Or, conversely, when self-development was felt to be more important, informal group and individual activities were more often chosen (although the separate effects of self-development on the proportions of informal and individual activities are non-significant).

In an additional analysis, we also analyzed the effect of being single (or more precise, living in a single-person household), thereby exploring the idea that the lack of a partner and/or children would affect the social context of people's leisure activities. However, we found no significant effects on the three proportions of Table 3.

As argued in the introductory section, the indicators in Table 3 may also explain the trends. Table 4 explores whether (population changes in) these variables explain informalization. The variables were entered in different models and the change in the coefficient of the year of measurement was analyzed (see 'data' section). We only entered the variables that showed significant effects (and the appropriate sign) in Table 3. Since the proportion of associational activities did not change, Table 4 also represents the inverse of the decrease in individual activities.

As Table 4 shows, informalization followed a pattern of cohort replacement. When cohort differences were entered in the model, the coefficient of the year of measurement was no longer significant, and was approximately zero. However, this is not really a substantive explanation, since it remains unknown what makes the cohorts different. The ageing of the population, on the other hand, suppressed the trend; after entering controls for age and age-squared, the year coefficient was $25 \%$ larger. Older people perform a slightly smaller share of their leisure activities in informal groups; the rise in life expectancy therefore suppresses the trend. Finally, the increase in average education level between 1975 and 2005 explained $44 \%$ of the informalization trend; the higher-educated more often participate in informal groups than the lower-educated, and their number has grown.

\section{Discussion and Conclusions}

In this paper, we tested the individualization and informalization hypotheses on leisure activities in The Netherlands between 1975 and 2005. In line with previous research (De 
Hart and Dekker 1999; Van den Berg and De Hart 2008), we found that the absolute number of leisure activities people perform in voluntary associations remained the same between 1975 and 2005. The conclusions are more solid than those in previous studies, however, as our data included a wide range of possible leisure activities (and thus many possible memberships) instead of one question on participation in leisure associations (the conventional indicator in many general surveys). Additionally, we argued that developments in the informal sphere and at individual leisure activities should also be taken into account in order to assess issues of decline-of-community. Our analyses showed that a process of informalization has taken place; the share of leisure activities performed in informal groups has grown. However, contrary to popular belief, this did not take place at the expense of activity in voluntary associations. Instead, the rise in informal group activity went hand in hand with a decrease in individual activities, while the share of leisure activities in voluntary associations remained the same. In other words, we did not find a (general) individualization trend. However, we also observed that specific domains of leisure can diverge from these general trends; for example, in the field of sports individual activities are gaining importance over associational activities.

This has some implications for future research. First, it can be read as a warning against drawing far-reaching conclusions based on membership numbers; we need to look at alternative social contexts as well. In the case of sports, we found that individualization is taking place, although the level of activity in associations increased slightly. Second, the consequences of informalization and individualization are likely to be very different. We know little about the side-effects of informal group participation vis-à-vis associational participation, but recently, Green and Brock (2005) found that participation in informal groups can help improve people's skills and enhance social resources, in ways that are partly similar to those of associations and partly different. It is unlikely that individual activities can bring about the same effects; while individual activities may still enhance certain (civic) skills (Schudson 2006; Van Ingen and Van Eijck 2009), they do not create social resources. It would be interesting for future research to elaborate on the different functions that informal groups and voluntary associations can fulfil, so that we know what we gain or lose when their importance increases or decreases.

Although our data provided a unique overview of the social contexts of leisure activities with a time span of 30 years, our study also has several limitations. One is that we analyzed the number of activities that people performed, not the duration of those activities. It might still be possible that individualization occurred in terms of the total time budget, i.e. if the duration of individual activities has expanded. Furthermore, our analyses did not include indicators of media use (which were not measured uniformly in all survey editions). It remains unclear how inclusion of these indicators would affect our conclusions; it is clear that the number of people who watch TV increased between 1975 and 2005, but on the other hand, the number of people who listen to the radio or read may have gone down at the same time. Finally, an important question is whether the developments we are dealing with are mainly shifts (of social contexts) within existing activities, or the result of a rise in popularity of activities with an inherent social context. The cross-sectional character of our data makes it hard to answer those questions. We have looked at developments within some of the sports that show a relatively equal distribution of the three social contexts, although the sample sizes are somewhat too small to provide information that is really reliable. Within these sports, we found little evidence of individualization, which implies-in line with previous research on sports in The Netherlands (Breedveld and Tiessen-Raaphorst 2006) - that the trend of individualization in sports we found is most likely the result of the rise of new and dominantly individual sports. However, increased informal activity can be witnessed in 
some of these sports (e.g. swimming, gymnastics, badminton), implying that for the trend of informalization substitutions of one context for the other has occurred. However, we would like to postpone our conclusions until more reliable data become available.

Our analyses also provided us with information about who chooses which social context and how this can help explain the observed trends. Younger cohorts undertook a higher proportion of informal group activities, but not necessarily a larger share of individual activities. Cohort replacement drove the informalization trend between 1975 and 2005. This also means that-if the differences between these cohorts are maintained-future cohort replacement will cause further informalization. Although our data do not allow us to explore further what causes the cohort differences, one obvious explanation that springs to mind is the rapid expansion of information and communication technology, which offers extended possibilities for maintaining social contacts. Younger cohorts are the first to embrace these new techniques, which not only make it easier for them to maintain their social networks, but also to mobilize people for leisure pursuits.

Education is also an important factor in the choice of certain leisure activities; the highly educated undertake a higher proportion of social activities (associational + informal context) than the lower-educated. This finding is in line with previous research, in which the highly educated were found to have larger social networks and greater social skills (Lin 2001) and to exhibit more pro-social behaviour in general (Gesthuizen et al. 2008). Education also helps explain the informalization trend between 1975 and 2005 , since the average education level of the population rose in this period and the highereducated show a greater proportion of informal group activity.

Finally, there are indications that the proportions of individual and informal group activities go up when associational activities do not provide sufficient flexibility or freedom of choice: respondents who endorsed the importance of self-development and respondents who faced time problems were less inclined to choose leisure activities in an associational context. This was also true for women and those who combine household and work tasks (either men or women). The main substitution for the associational activities seems to be individual activities among these groups; informal activities remain largely unaffected by structural constraints.

In conclusion, we have shown for the period 1975-2005 that there has not been a decline in social involvement in the field of leisure; people have not increasingly turned to individual leisure activities. However, there has been a change in the nature of social activities: informal group activities are gaining importance (while associational activity remains the same). Given these results, there is no reason to fear the dissolution of associational life, as our title somewhat provocatively suggested, but-as scientific researchers-we may want to expand the topic of our study, and not only consider participation in voluntary associations, but also participation in informal settings. The degree to which these consist of similar interactions and the degree to which they have similar outcomes deserve attention in future research.

Open Access This article is distributed under the terms of the Creative Commons Attribution Noncommercial License which permits any noncommercial use, distribution, and reproduction in any medium, provided the original author(s) and source are credited.

\section{References}

Andersen, R., Curtis, J. E., \& Grabb, E. G. (2006). Trends in civic association activity in four democracies: The special case of women in the United States. American Sociological Review, 71, 376-400. 
Bauman, Z. (2002). Individually, together (Foreword). In U. Beck \& E. Beck-Gernsheim (Eds.), Individualization: Institutionalized individualism and its social and political consequences. London: Sage.

Beck, U., \& Beck-Gernsheim, E. (2002). Individualization: Institutionalized individualism and its social and political consequences. London: Sage.

Breedveld, K. (2000). Social and cultural planning office; Time use survey 1975, 1980, 1985, 1990, 1995, 2000 [computerfiles]. Amsterdam: Steinmetz Archives (P1576).

Breedveld, K., \& Tiessen-Raaphorst, A. (Eds.). (2006). Rapportage Sport 2006 [Report on Sport 2006]. Den Haag: The Netherlands Institute for Social Research.

Castells, M. (2000). The rise of the network society. Oxford: Blackwell.

Curtis, J. E., Baer, D. E., \& Grabb, E. G. (2001). Nations of joiners: Explaining voluntary association membership in democratic societies. American Sociological Review, 66(6), 783-805.

De Beer, P. (2007). How individualized are the Dutch? Current Sociology, 55(3), 389-413.

De Hart, J. (2001). Religion and volunteering in The Netherlands. In P. Dekker \& E. M. Uslaner (Eds.), Social capital and participation in everyday life. London: Routledge.

De Hart, J. (2005). Landelijk Verenigd. Den Haag: The Netherlands Institute for Social Research.

De Hart, J., \& Dekker, P. (1999). Civic engagement and volunteering in The Netherlands-A 'Putnamian' analysis. In J. W. Van Deth, M. Maraffi, K. Newton, \& P. F. Whiteley (Eds.), Social capital and European democracy. London: Routledge.

Dekker, P. (2004). The sphere of voluntary associations and the ideals of civil society: A West-European perspective. Korea Observer, 35(3), 391-415.

Dekker, P., \& Hooghe, M. (2003). De burger-nachtwaker: Naar een informalisering van de politieke participatie van de Nederlandse en Vlaamse bevolking. Sociologische Gids, 50(2), 156-181.

Fischer, C. S. (2005). Bowling alone: What's the score? Social Networks, 27, 155-167.

Fuchs, D., \& Klingemann, H.-D. (1995). Citizens and the state: A changing relationship? In H.-D. Klingemann \& D. Fuchs (Eds.), Citizens and the state. Oxford: Oxford University Press.

Gesthuizen, M., Van der Meer, T., \& Scheepers, P. (2008). Education and dimensions of social capital: Do educational effects differ due to educational expansion and social security expenditure? European Sociological Review, 24(5), 617-632.

Glanville, J. (2004). Voluntary associations and social network structure: Why organizational location and type are important. Sociological Forum, 19(3), 465-491.

Green, M. C., \& Brock, T. C. (2005). Organizational membership versus informal interaction: Contributions to skills and perceptions that build social capital. Political Psychology, 26(1), 1-25.

Halpern, D. (2005). Social capital. Cambridge: Polity Press.

Hustinx, L. (2005). Weakening organizational ties? A classification of styles of volunteering in the Flemish red cross. Social Service Review, 79(4), 624-652.

Hustinx, L., \& Lammertyn, F. (2003). Collective and reflexive styles of volunteering: A sociological modernization perspective. Voluntas, 14(2), 167-187.

Inglehart, R. (1997). Modernization and postmodernization: Cultural, economic, and political change in 43 societies. Princeton: Princeton University Press.

Inglehart, R., \& Baker, W. E. (2000). Modernization, cultural change, and the persistence of traditional values. American Sociological Review, 65(1), 19-51.

Kwak, N., Shah, D. V., \& Holbert, R. L. (2004). Connecting, trusting, and participating: The direct and interactive effects of social associations. Political Research Quarterly, 57(4), 643-652.

Lin, N. (2001). Social capital: A theory of social structure and action. Cambridge: Cambridge University Press.

Newton, K. (1999). Social capital and democracy in modern Europe. In J. V. Deth (Ed.), Social capital and European democracy (pp. 3-24). London: Routledge.

O'Conner, J. P. (2007). Real cyclists don't race. International Review for the Sociology of Sport, 42(1), 83-97.

Paxton, P. (1999). Is social capital declining in the United States? A multiple indicator assessment. American Journal of Sociology, 105(1), 88-127.

Paxton, P., Kunovich, S., \& Hughes, M. H. (2007). Gender in politics. Annual Review of Sociology, 33, 263284.

Pichler, F., \& Wallace, C. (2007). Patterns of formal and informal social capital in Europe. European Sociological Review, 23(4), 423-435.

Putnam, R. D. (1995a). Bowling alone: America's declining social capital. Journal of Democracy, 6(1), $65-78$.

Putnam, R. D. (1995b). Tuning in, tuning out: The strange disappearance of social capital in America. Political Science \& Politics, 28(4), 664-683. 
Putnam, R. D. (2000). Bowling alone: The collapse and revival of American community. New York: Simon \& Schuster.

Rotolo, T. (1999). Trends in voluntary association participation. Nonprofit and Voluntary Sector Quarterly, 28(2), 199-212.

Ryan, V. D., Agnitsch, K. A., Zhao, L., \& Mullick, R. (2005). Making sense of voluntary participation: A theoretical synthesis. Rural Sociology, 70(3), 287-313.

Schudson, M. (1998). The good citizen: A history of American civic life. New York: Free Press.

Schudson, M. (2006). The varieties of civic experience. Citizenship Studies, 10(5), 591-606.

Skocpol, T. (2003). Diminished democracy. Norman: University of Oklahoma Press.

Social and Cultural Planning Office. (2003). Aanvullend Voorzieningengebruiksonderzoek 2003-AVO'03 [computerfile]. Amsterdam: Steinmetz Archives (P1660).

Southerton, D., \& Tomlinson, M. (2005). Pressed for time-The differential impacts of a time squeeze. Sociological Review, 53(2), 215-239.

Stolle, D., Hooghe, M. R. J., \& Micheletti, M. (2005). Politics in the supermarket: Political consumerism as a form of political participation. International Political Science Review, 26(3), 245-269.

Stolle, D., \& Rochon, T. R. (1998). Are all associations alike? The American Behavioral Scientist, 42(1), 47-65.

Van den Berg, E., \& De Hart, J. (2008). Maatschappelijke organisaties in beeld. Den Haag: The Netherlands Institute for Social Research.

Van der Lippe, T. (2007). Dutch workers and time pressure: Household and workplace characteristics. Work, Employment \& Society, 21(4), 693-711.

Van Ingen, E. (2008). Social participation revisited: Disentangling and explaining period, life-cycle and cohort effects. Acta Sociologica, 51(2), 103-121.

Van Ingen, E., Stoop, I., \& Breedveld, K. (2009). Nonresponse in the Dutch time use survey: Strategies for response enhancement and bias reduction. Field Methods, 21(1), 69-90.

Van Ingen, E., \& Van Eijck, K. (2009). Leisure and social capital: An analysis of types of company and activities. Leisure Sciences, 31(2), 192-206.

Wellman, B. (2001). Physical place and cyberplace: The rise of personalized networking. International Journal of Urban and Regional Research, 25(2), 227-252.

Wollebaek, D., \& Selle, P. (2005). Women's power under threat? Voluntary organizations in transition. In S. Roßteutscher (Ed.), Democracy and the role of associations: Political, organizational and social contexts. London: Routledge.

Wuthnow, R. (1994). Sharing the journey: Support groups and America's new quest for community. New York: Free Press.

Wuthnow, R. (1998). Loose connections: Joining together in America's fragmented communities. Cambridge: Harvard University Press. 